OPEN ACCESS

Edited by:

Ling Liu,

Southeast University, China

Reviewed by:

Yuetian Yu,

Shanghai Jiao Tong University, China

Zhengyuan Xia,

The University of Hong Kong,

Hong Kong SAR, China

*Correspondence:

Pien Swart

p.swart@amsterdamumc.nl

${ }^{+} P$ Ractice of VENTilation in patients with COVID-19; Collaborators are presented at the end of the article

Specialty section: This article was submitted to Intensive Care Medicine and

Anesthesiology,

a section of the journal

Frontiers in Medicine

Received: 20 September 2021 Accepted: 30 November 2021

Published: 03 January 2022

Citation:

Swart P, Nijbroek SGLH, Paulus F, Neto AS and Schultz MJ (2022) Sex

Differences in Use of Low Tidal Volume Ventilation in COVID-19-Insights From the

PROVENT-COVID Study.

Front. Med. 8:780005.

doi: 10.3389/fmed.2021.780005

\section{Sex Differences in Use of Low Tidal Volume Ventilation in COVID-19-Insights From the PRoVENT-COVID Study}

\author{
Pien Swart ${ }^{1 *}$, Sunny G. L. H. Nijbroek ${ }^{1,2}$, Frederique Paulus ${ }^{1}$, Ary Serpa Neto ${ }^{1,3,4}$ and \\ Marcus J. Schultz ${ }^{1,5,6}$ for the 'PRactice of VENTilation in COVID-19' (PRoVENT-COVID) \\ Collaborative Group ${ }^{+}$

\begin{abstract}
'Department of Intensive Care, Amsterdam University Medical Center, Location 'Academic Medical Center', Amsterdam, Netherlands, ' Department of Anaesthesiology, Amsterdam University Medical Center, Location 'Academic Medical Center', Australia, ${ }^{4}$ Department of Critical Care Medicine, Hospital Israelita Albert Einstein, São Paulo, Brazil, ${ }^{5}$ Mahidol Oxford Tropical Medicine Research Unit (MORU), Mahidol University, Bangkok, Thailand, ${ }^{6}$ Nuffield Department of Medicine, University of Oxford, Oxford, United Kingdom
\end{abstract} \\ Amsterdam, Netherlands, ${ }^{3}$ Australian and New Zealand Intensive Care Research Centre, Monash University, Melbourne, VIC,
}

The purpose of this study was to compare and understand differences in the use of low tidal volume ventilation (LTVV) between females and males with acute respiratory distress syndrome (ARDS) related to coronavirus disease 2019 (COVID-19). This is a post-hoc analysis of an observational study in invasively ventilated patients with ARDS related to COVID-19 in 22 ICUs in the Netherlands. The primary endpoint was the use of LTVV, defined as having received a median tidal volume $\left(\mathrm{V}_{T}\right) \leq 6 \mathrm{ml} / \mathrm{kg}$ predicted body weight (PBW) during controlled ventilation. A mediation analysis was used to investigate the impact of anthropometric factors, next to the impact of sex per se. The analysis included 934 patients, 251 females and 683 males. All the patients had ARDS, and there were no differences in ARDS severity between the sexes. On the first day of ventilation, females received ventilation with a higher median $\mathrm{V}_{T}$ compared with males [6.8 (interquartile range (IQR) 6.0-7.6 vs. 6.3 (IQR 5.8-6.9) ml/kg PBW; $p<0.001$ ]. Consequently, females received LTV less often than males (23 vs. 34\%; $p=0.003$ ). The difference in the use of LTV became smaller but persisted over the next days ( $27 \mathrm{vs.} 36 \% ; p=0.046$ at day 2 and 28 vs. 38\%; $p=0.030$ at day 3). The difference in the use LTV was significantly mediated by sex per se [average direct effect of the female sex, $7.5 \%(95 \% \mathrm{Cl}, 1.7-$ $13.3 \%) ; p=0.011$ ] and by differences in the body height [average causal mediation effect, $-17.5 \%$ (-21.5 to $-13.5 \%) ; p<0.001$ ], but not by the differences in actual body weight [average causal mediation effect, $0.2 \%$ ( -0.8 to $1.2 \%) ; p=0.715$ ]. In conclusion, in this cohort of patients with ARDS related to COVID-19, females received LTV less often than males in the first days of invasive ventilation. The difference in the use of LTV was mainly driven by an anthropometric factor, namely, body height. Use of LTV may improve by paying attention to correct titration of $\mathrm{V}_{\mathrm{T}}$, which should be based on PBW, which is a function of body height.

Keywords: lung protective ventilation, low tidal volume ventilation (LTVV), sex, gender, COVID-19, intensive care unit, critical care, mechanical ventilation 


\section{INTRODUCTION}

Coronavirus disease 2019 (COVID-19) pandemic continues to have a relentless impact on the healthcare systems worldwide. Critical care systems are overloaded as many patients with COVID-19 develop acute respiratory failure requiring admission to a hospital for supplementary oxygen. A substantial proportion of these patients need admission to an intensive care unit (ICU) for ventilatory support $(1,2)$. Lung-protective ventilation, including the use of a low tidal volume $\left(\mathrm{V}_{\mathrm{T}}\right)$, is recommended in patients with acute respiratory distress syndrome $(\operatorname{ARDS})(3,4)$ and there is growing evidence that the use of low $-\mathrm{V}_{\mathrm{T}}$ ventilation (LTVV) also benefits patients with ARDS related to COVID-19 $(5,6)$.

Differences between females and males with regard to the use of LTVV have been described in surgery patients during general anesthesia (7-12) as well as critically ill patients in the ICU-and irrespective of the presence of ARDS $(13-16,44)$. It is uncertain if the sex difference in the use of LTVV also exists in patients with COVID-19. Use of LTVV might be limited in these patients because, due to the large numbers of patients requiring respiratory support, ventilation may need to be provided by healthcare professionals with much less experience in invasive ventilation, and thus also in the use of LTVV-it is uncertain whether this translates into sex differences.

To compare ventilation management with respect to LTVV in females vs. males, we reassessed the database of a conveniently-sized national multicenter study named "PRactice of VENTilation in patients with COVID-19" (PRoVENTCOVID) (5), a study that focused on ventilator settings and ventilation parameters in the first 4 calendar days of ventilation. Next to the hypothesis that the use of LTVV differs between the sexes, we also tested the hypothesis that differences in LTVV use are driven by anthropometric differences, i.e., differences in height and weight between the sexes, more than by sex per se.

\section{MATERIALS AND METHODS}

\section{Design, Setting, and Participants}

Secondary analysis of the database from the PRoVENTCOVID study, an investigator-initiated, national, multicenter, observational study in 22 ICUs in the Netherlands in the first 3 months of the national outbreak (5).

The protocol of the study of PRoVENT-COVID was approved by the institutional review boards of each participating hospital-need for individual patient informed consent was waived seen the observational design of the investigation. The PRoVENT-COVID study was registered at clinicaltrial.gov under the identifier NCT04346342.

Consecutive patients aged 18 years or older were enrolled if admitted to an ICU in one of the participating hospitals and having had received invasive ventilation for acute respiratory failure due to COVID-19, which had to be confirmed by RT-PCR. The PRoVENT-COVID study excluded SARS-CoV-2 infected patients that received ventilation for other reasons than COVID-19, e.g., patients that received ventilation for postoperative ventilation.

\section{Data Collection and Analysis}

Demographics, home medication, comorbidities, and disease severity scores were collected at baseline. The Berlin definition for ARDS was used to determine whether a patient had ARDS, and for ARDS severity (17).

Detailed information regarding ventilation management was captured in the first 4 calendar days of invasive ventilation at fixed time points every $8 \mathrm{~h}$. Pulmonary and extrapulmonary events were captured up to hospital discharge, with a maximum of 28 days. Outcomes, such as intubation and life status, were collected till day 90 .

We used the following equations:

$\mathrm{V}_{\mathrm{T}}$ normalized to predicted body weight (PBW) ( $\left.\mathrm{V}_{\mathrm{T}, \mathrm{PBW}}\right)$

$$
[\mathrm{ml} / \mathrm{kg}]=\text { absolute } \mathrm{V}_{\mathrm{T}}(\mathrm{ml}) / \mathrm{PBW}(\mathrm{kg})(18) ;(1)
$$

PBW in females $(\mathrm{kg})=45.5+0.91^{*}$ (height $\left.[\mathrm{cm}]-152.4\right)$;

and PBW in males $(\mathrm{kg})=50.0+0.91^{*}($ height $[\mathrm{cm}]-152.4)$;

$\mathrm{V}_{\mathrm{T}}$ normalized to actual body weight (ABW) ( $\left.\mathrm{V}_{\mathrm{T}, \mathrm{ABW}}\right)$

$[\mathrm{ml} / \mathrm{kg}]=$ absolute $\mathrm{V}_{\mathrm{T}}(\mathrm{ml}) / \mathrm{ABW}(\mathrm{kg})$

driving pressure $(\Delta \mathrm{P})\left[\mathrm{cm} \mathrm{H}_{2} \mathrm{O}\right]=$ peak pressure (Ppeak)

[cm $\left.\mathrm{H}_{2} \mathrm{O}\right]$ - PEEP [ $\left.\mathrm{cm} \mathrm{H} \mathrm{H}_{2} \mathrm{O}\right]$; and

respiratory system compliance $(\mathrm{Crs})\left[\mathrm{ml} / \mathrm{cm} \mathrm{H}_{2} \mathrm{O}\right]$

$=$ Absolute $\mathrm{V}_{\mathrm{T}}(\mathrm{ml}) / \Delta \mathrm{P}\left[\mathrm{cm} \mathrm{H} \mathrm{H}_{2} \mathrm{O}\right]$

\section{Study Endpoints}

The primary endpoint was the use of LTVV in the first 4 calendar days of invasive ventilation. Secondary endpoints were other key ventilation parameters, including absolute $\mathrm{V}_{\mathrm{T}}, \mathrm{V}_{\mathrm{T}, \mathrm{ABW}}$ and $\mathrm{V}_{\mathrm{T}, \mathrm{PBW}}$, PEEP, $\triangle \mathrm{P}$, and Crs.

\section{Power Calculation}

The PRoVENT-COVID study contains a conveniently sized cohort of patients. We did not perform a formal power calculation; the sample size was based on the number of patients available in the database. With 1,000 patients, the study has $>80 \%$ power to detect an absolute difference ranging from 9 and $15 \%$ in the use of LTVV considering a use rate of $50 \%$ in the female patients as shown previously (16).

\section{Statistical Analysis}

No assumptions were made for missing data. As the first calendar day was a flexible day that lasted from the moment of intubation and start of ventilation in the participating ICU and in theory could last from $1 \mathrm{~min}$ to $23 \mathrm{~h}$ and $59 \mathrm{~min}$, we merged the first and second calendar day, which was then named "day 1." The following calendar days were named "day 2" and "day 3." As the ventilation strategy and settings may vary substantially in the first 


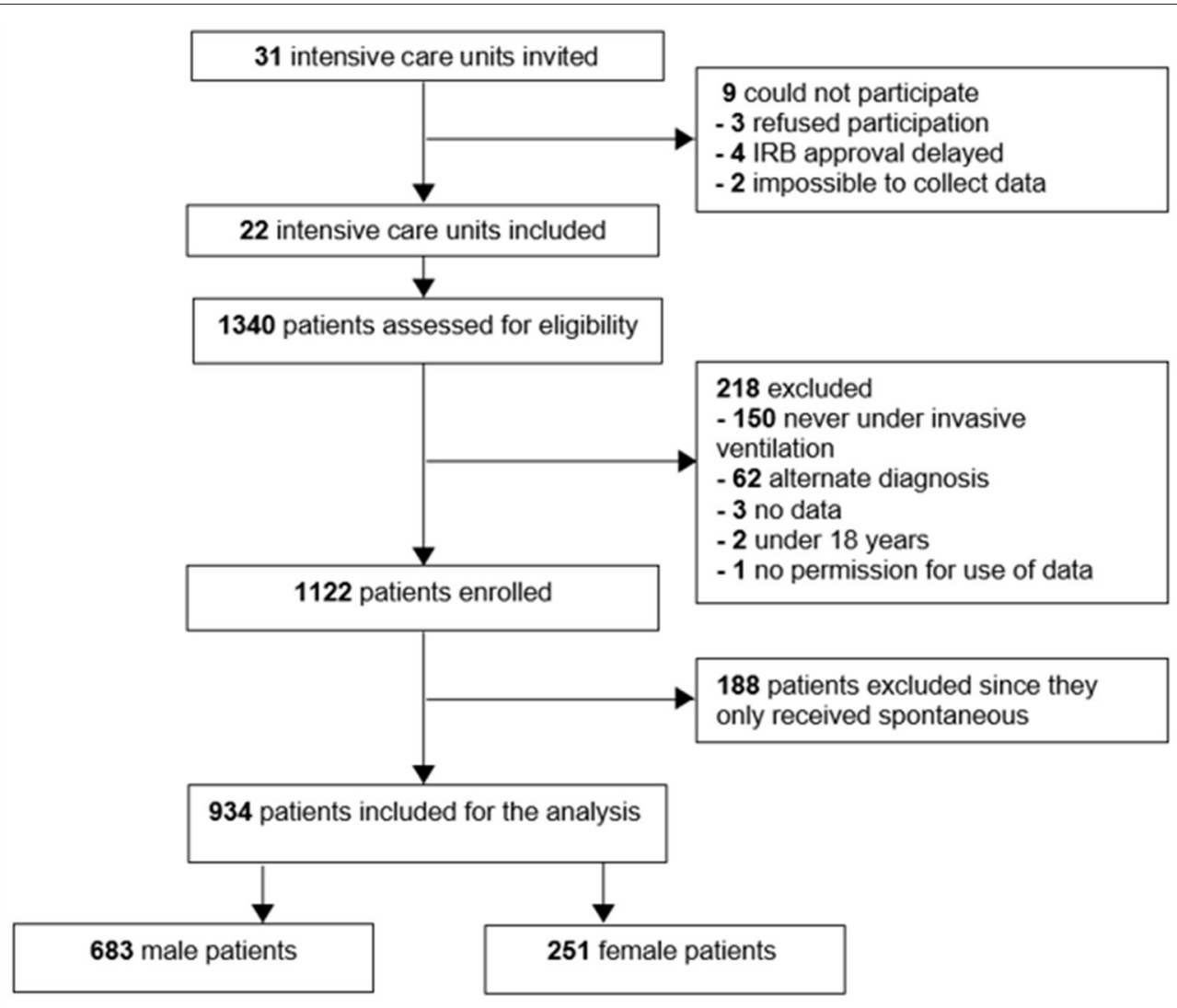

FIGURE 1 | Study flowchart.

hour of intubation, we also ignored the first available $V_{T}$, i.e., collected within $1 \mathrm{~h}$ of intubation.

Data are reported as numbers and proportions for categorical variables, and as medians with interquartile ranges (IQRs) for continuous variables. In addition, we also provided the $90 \%$ range for $\mathrm{V}_{\mathrm{T}}$. For baseline characteristics, the sexes were compared using the Fisher exact test for categorical variables, and the Wilcoxon rank-sum test for continuous variables. In all the analyses, males are used as the reference.

Ventilation parameters per day are presented in cumulative distribution plots, and in line graphs with error bars. In the distribution plots, vertical dotted lines represent the ideal cutoff for each parameter, and horizontal dotted lines the respective proportion of patients reaching each cutoff. All the ventilatory variables were aggregated per day and reported as such. For this, we calculated the mean of each ventilatory parameter per patient per day. In the tables, continuous variables were reported as medians of the means per each patient.

Patients were classified as having received LTVV, if the mean $\mathrm{V}_{\mathrm{T}, \mathrm{PBW}}$ was $\leq 6 \mathrm{ml} / \mathrm{kg}$ during the controlled ventilation. For day 1 , we ignored the breath in the first hour of ventilation, as this breath could have not been adjusted to achieve LTVV, e.g., in patients who started ventilation in the emergency department. Breaths collected under pressure support ventilation were also ignored, as were a breath that was collected at the moment spontaneous breathing activity was likely. This was the case if the measured (total) RR exceeded the set RR $>2$ breaths per min.

To further assess if sex is associated with differences in $V_{T}$ an unadjusted mixed-effects linear regression model was used to extract the risk difference among the sexes. All analyses were performed using multilevel (patients nested in hospitals), mixed modeling with hospitals as a random effect to account for withincenter clustering. Two $P$-values were reported in the graphs: (1) $P$-value for sex differences, reflecting the overall test for difference between sex across the days; and (2) $p$-values for the sex $\times$ day interaction, evaluating if change over time differed between the sexes.

The proportions of patients having had received LTVV are described and visualized in pie charts. An unadjusted mixedeffect generalized linear model was used to extract the risk difference for LTVV use.

To investigate whether differences in the use of LTVV between females and males are mediated by body height and ABW, a mixed-effect mediation model was used. In the mediation analysis, we assessed the individual impact of body height and ABW as potential mediators for the difference in the use of LTVV between sex. Mediators are variables that are affected by group assignment and that subsequently can affect the outcome. 
TABLE 1 | Baseline characteristics of patient.

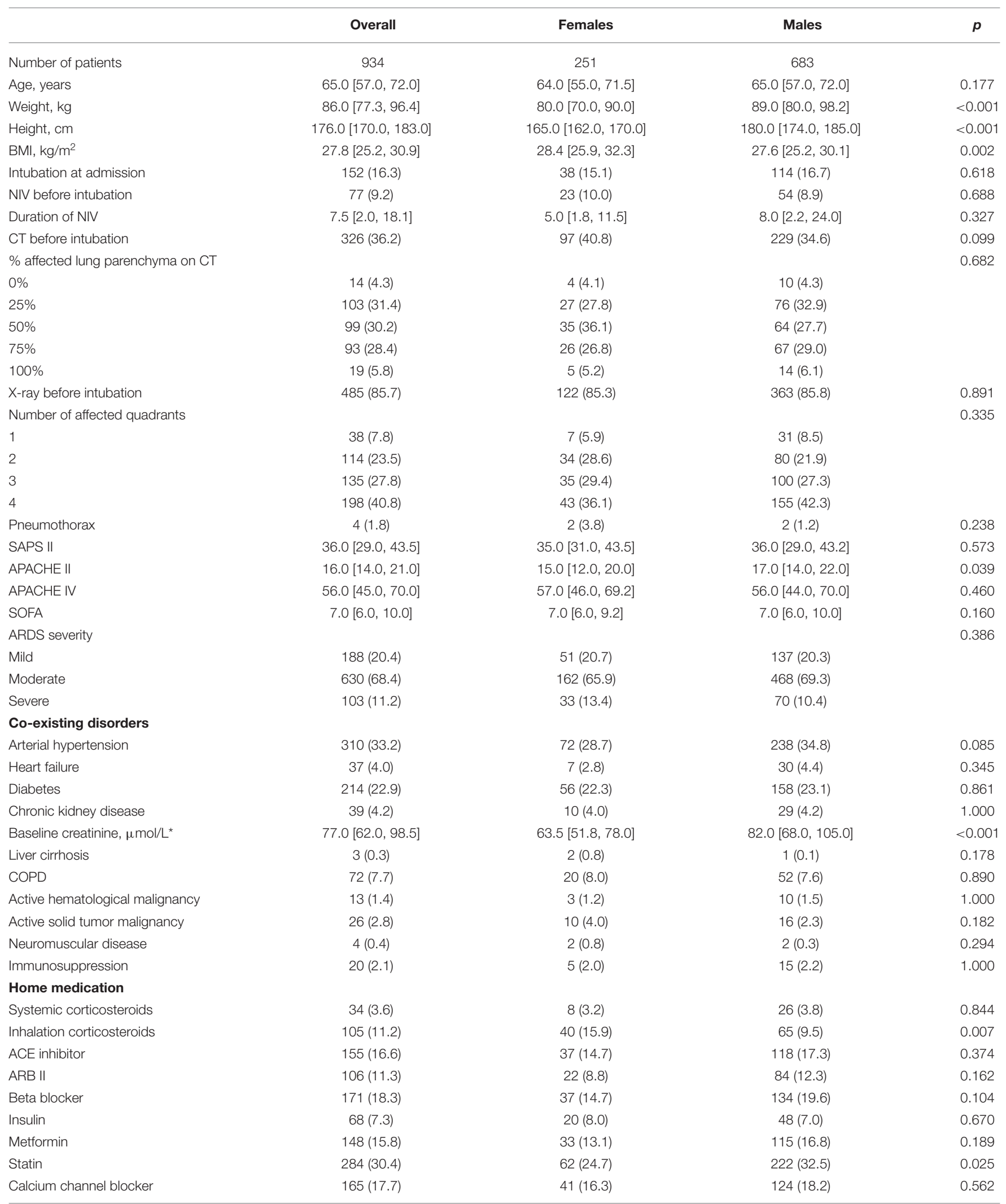

Data are median (quartile $25 \%$-quartile $75 \%$ ) or no (\%). Percentages may not total 100 because of rounding.

"Most recent measurement in $24 \mathrm{~h}$ before intubation, or at ICU admission under invasive ventilation.

APACHE, Acute Physiology and Chronic Health Evaluation; SAPS, Simplified Acute Physiology Score; SOFA, Sequential Organ Failure Assessment; ARDS, acute respiratory distress syndrome. 
Therefore, mediators are on the causal pathway of the relation between group and outcome, at least partly explaining the effects of the group on the outcome. For the mediation models, the following estimates are described: (1) the total effect (estimates the total effect of sex on ventilation); (2) the average causal mediation effect [ACME, explains how much of the effect of sex on ventilation is explained by the mediator (height or weight)]; and (3) the average direct effect (ADE, explains how much of the effect of sex on ventilation is still explained by sex after considering the effect of the mediator). For this model, QuasiBayesian 95\% CI were estimated after 10,000 simulations. The mediation models included day and centers as a random effects.

All the analyses were done in $\mathrm{R}$ version 4.0.2 and the significance level was set at 0.05 .

\section{RESULTS}

\section{Patients}

Of 1,122 eligible patients, 188 patients did not receive controlled ventilation at any time point data were collected for this study, leaving us with 934 fully analyzable patients, 251 females and 683 males (Figure 1). Males had a higher median body height and also a higher median ABW. Aside from differences in baseline APACHE II scores, plasma creatinine, and use of statins and inhalation corticosteroids at home, there were no differences at baseline between the sexes (Table 1). Other severity scores and ARDS severity were comparable between females and males (Table 1). Compared with females, males had a higher mortality rate and a longer duration of ventilation (Table 2).

\section{Ventilation Parameters}

On day 1, females received a higher median $\mathrm{V}_{\mathrm{T}, \mathrm{PBW}}$ than males [6.8 (IQR 6.0-7.6, 90\% range 5.4-8.8) vs. 6.3 (IQR 5.8$6.9,90 \%$ range $5.0-8.0) \mathrm{ml} / \mathrm{kg}$ PBW; $p<0.001$; Figures 2, 3 and Table 3]. This sex difference became smaller at day 2 [6.4 (IQR 5.9-7.1, 9\% range 5.0-8.4) vs. 6.3 (IQR 5.8-7.0, 90\% range $5.0-7.9) \mathrm{ml} / \mathrm{kg} \mathrm{PBW} ; p=0.046]$ and at day 3 [6.5 (IQR $6.0-7.1,90 \%$ range $5.1-8.2$ ) vs. 6.2 (IQR 5.6-6.9; 90\% range 4.9-7.8) $\mathrm{ml} / \mathrm{kg}$ PBW; $p=0.001$; Supplementary Figures 1, 2 and Supplementary Tables 1,2]. On day 1, females received ventilation with a slightly lower median PEEP and a higher median $\Delta \mathrm{P}$ (Figures 2, 3 and Table 3). These differences became smaller on days 2 and 3 (Supplementary Figures 1, 2 and Supplementary Tables 1, 2). Median Crs was lower in females at all 3 days.

\section{Use of LTVV}

Low tidal volume ventilation was generally underused, with only a third of patients receiving ventilation with a median $\mathrm{V}_{\mathrm{T}, \mathrm{PBW}}$ $\leq 6 \mathrm{ml} / \mathrm{kg}$ PBW-at day 1 , females received LTVV less often than males ( 23 vs. $34 \% ; p=0.003$; Figure 4 ). The sex difference in use

TABLE 2 | Outcome.

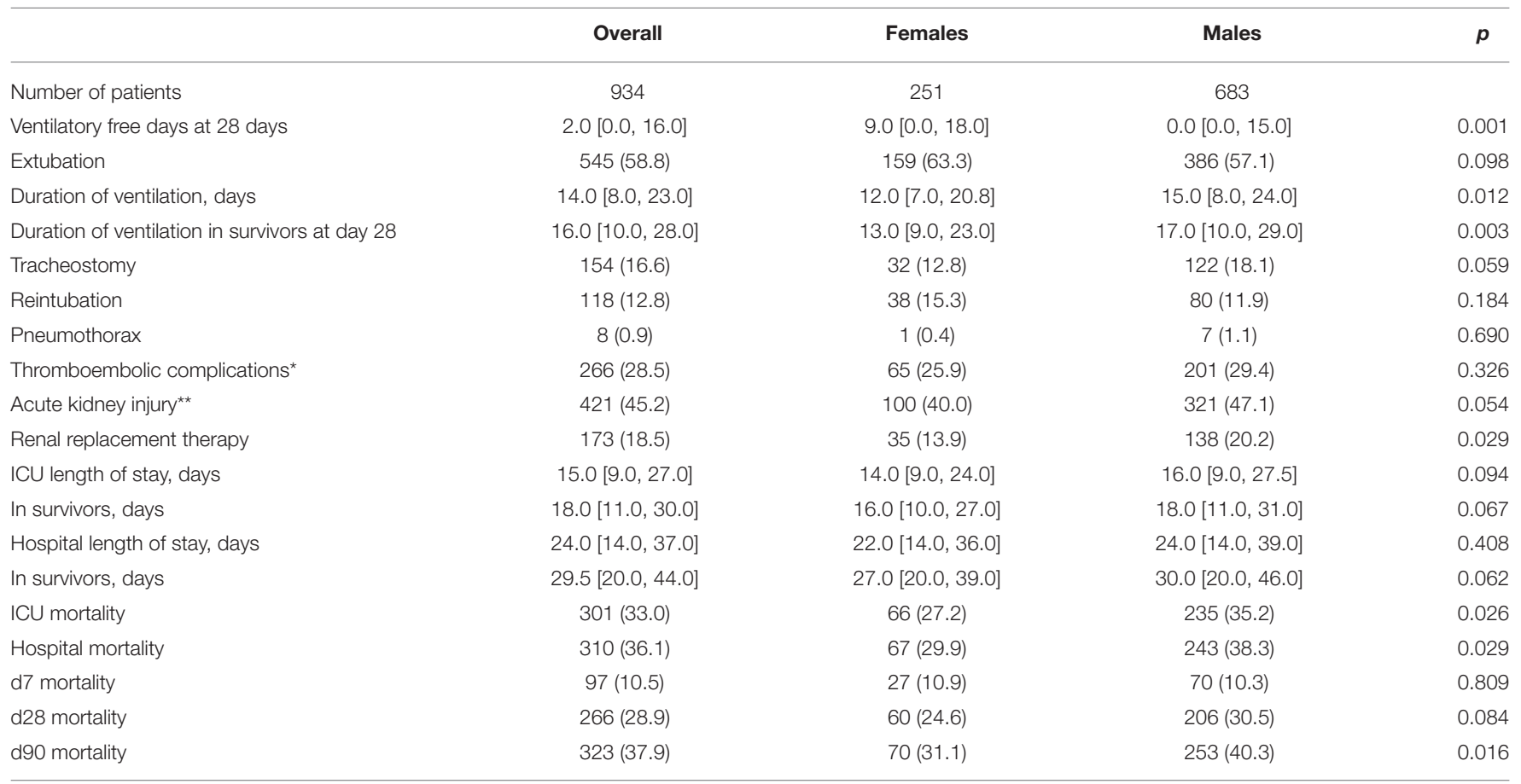

Data are median (quartile 25\%-quartile $75 \%$ ) or no (\%). Percentages may not total 100 because of rounding.

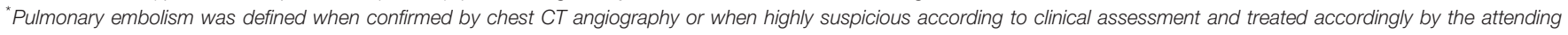
the physician.

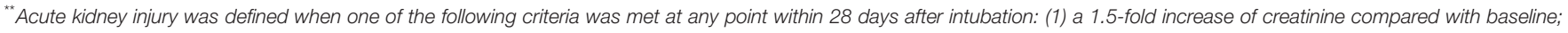
and/or (2) an absolute creatinine increase of $26.5 \mu \mathrm{mol} / \mathrm{L}$ compared with baseline; and/or (3) a urinary output $<0.5 \mathrm{ml} / \mathrm{kg}$ per $\mathrm{h}$ for more than $6 \mathrm{~h}$. 

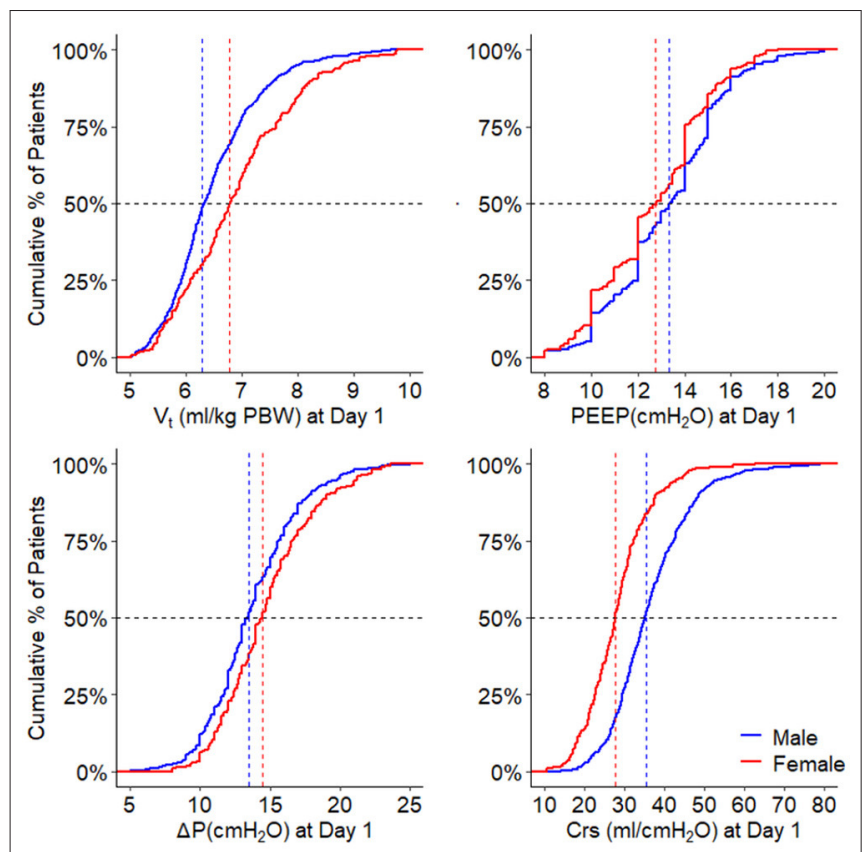

FIGURE 2 | Ventilation parameters during the first day. Cumulative frequency distribution of tidal volume, PEEP, driving pressure, and respiratory system compliance. Vertical dotted lines represent the median on the first calendar day of ventilation for each variable, and horizontal dotted lines show the respective proportion of patients reaching each cutoff. $V_{T}$, tidal volume; PEEP, positive end expiratory pressure; $\Delta \mathrm{P}$, driving pressure; $\mathrm{Crs}$, respiratory system compliance; PBW, predicted body weight. The $p$-value for the sex reflects the overall test for difference between sex over the days, the $p$-value for the $\operatorname{sex} x$ year interaction evaluates if change over time differed by sex.

of LTVV persisted at day 2 (27 vs. $36 \% ; p=0.046)$ and at day 3 (28 vs. 38\%; $p=0.030$; Figure 4 and Supplementary Tables 1, 2).

\section{Mediation Analysis}

The difference in the use of LTVV between females and males was significantly mediated by sex [average causal mediation effect $7.5 \%$ (95\% CI $1.7-13.3 \%) ; p=0.011$ ] but more by body height [average causal mediation effect $-17.5 \%$ (95\% CI -21.5 to $-13.5 \%) ; p<0.001$; Table 4]. The difference was also significantly mediated by ABW in the model that only used this factor [average causal mediation effect $-1.7 \%$ (95\% CI -2.7 to $-1.0) ; p<0.001$ ], but not in a model that also used body height, meaning that the difference in the use of LTVV was mainly mediated by differences in height, and not by weight.

\section{DISCUSSION}

The results of this analysis of a large cohort of critically ill patients with ARDS related to COVID-19 who received invasive ventilation in the ICU during the first wave of the national outbreak in the Netherlands can be summarized as follows: (1) females were at a higher risk of not receiving LTVV at all 4 days of ventilation; (2) PEEP was lower and $\triangle \mathrm{P}$ was higher, but only at day 1; and (3) females had a lower Crs, a difference that did not change over the days. In addition, the mediation analysis suggests

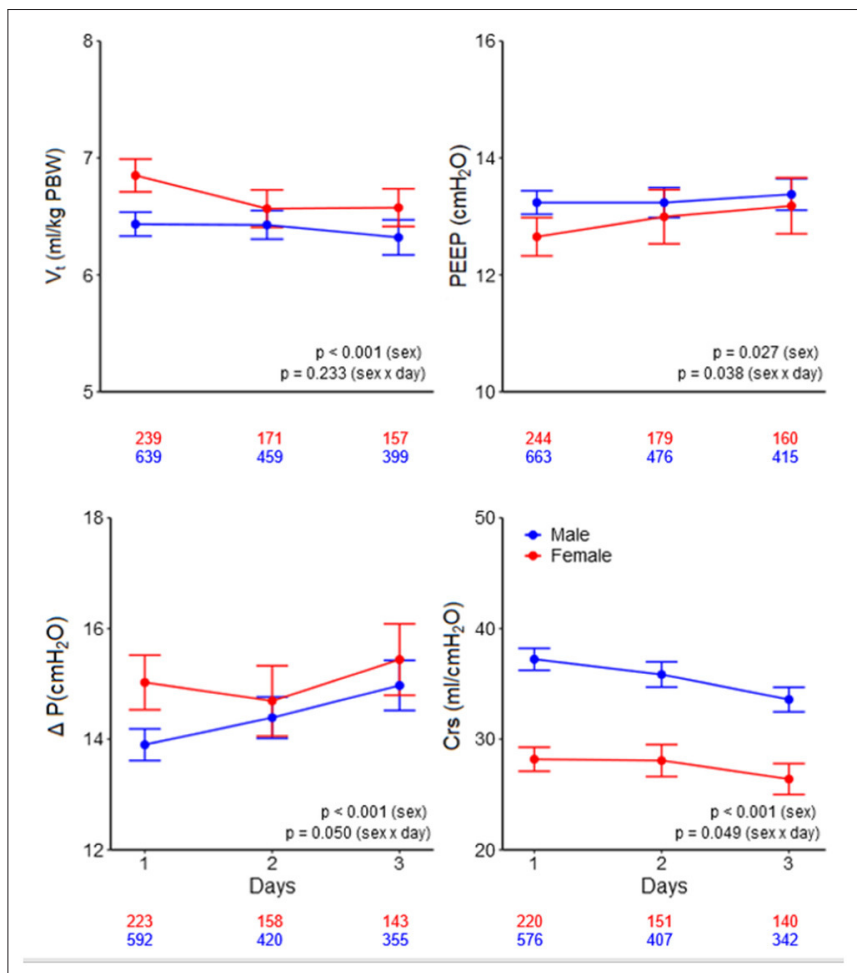

FIGURE 3 | Ventilatory variables over the days. Line graphs with error bars of tidal volume, PEEP, driving pressure, and respiratory system compliance. The numbers under the $\mathrm{x}$-axis indicate the number of patients. $\mathrm{V}_{\mathrm{T}}$, tidal volume; PEEP, positive end-expiratory pressure; $\Delta \mathrm{P}$, driving pressure; Crs, respiratory system compliance; PBW, predicted body weight. The $p$-value for the sex reflects the overall test for difference between sex over the days, the $p$-value for the sex $x$ year interaction evaluates if change over time differed by sex.

that (4) differences are partly explained by sex per se; (5) but are mostly explained by the differences in body height.

Our study has several strengths. The PRoVENT-COVID study is one of the largest multicenter studies that collected ventilator data at several time points per day, allowing a better insight into ventilation practice, and differences herein between females and males. This study involved more than onethird of all invasively ventilated patients with ARDS related to COVID-19 in the first wave of the outbreak in the Netherlands. Furthermore, we enrolled patients in 22 centers included university hospitals, non-university teaching as well as nonteaching hospitals, accounting for around one-fourth of the ICUs in the Netherlands. This all increases the generalizability of the findings. The design of PRoVENT-COVID assured completeness of data collection and the short timeframe within which data were gathered, avoiding the effect of practice changes over time. At last, we followed the analysis plan strictly and used sophisticated mediation analysis to determine which factors determine the sex difference in the use of LTVV.

The differences in $V_{T}$ between females and males may seem small, especially when focusing on the median $V_{T}, P B W$. However, the $90 \%$ range clearly shows that $\mathrm{V}_{\mathrm{T}}$ differs between the sexes-for instance, $16 \%$ of female patients received ventilation with a $\mathrm{V}_{\text {T,PBW }}>8 \mathrm{ml} / \mathrm{kg}$, while only $5 \%$ of male patients received 
TABLE 3 | Ventilatory variables during the first day.

\begin{tabular}{|c|c|c|c|c|}
\hline & Overall & Females & Males & $p$ \\
\hline Number of patients & $908^{*}$ & 244 & 664 & \\
\hline $\mathrm{V}_{\mathrm{T}}$, Absolute, $\mathrm{mL}$ & $451.0[406.1,500.0]$ & $396.5[343.8,440.5]$ & $468.5[427.2,514.8]$ & $<0.001$ \\
\hline $\mathrm{V}_{\mathrm{T}}, \mathrm{mL} / \mathrm{kg} \mathrm{ABW}$ & $5.2[4.6,5.9]$ & $4.9[4.2,5.8]$ & $5.3[4.6,6.0]$ & $<0.001$ \\
\hline $90 \%$ range & $3.4-7.1$ & $3.3-7.0$ & $3.8-7.2$ & \\
\hline $\mathrm{V}_{\mathrm{T}}, \mathrm{mL} / \mathrm{kg} \mathrm{PBW}$ & $6.4[5.9,7.1]$ & $6.8[6.0,7.6]$ & $6.3[5.8,6.9]$ & $<0.001$ \\
\hline $90 \%$ range & $5.1-8.4$ & $5.4-8.8$ & $5.0-8.0$ & \\
\hline $\mathrm{V}_{\mathrm{T}}, \mathrm{PBW} \leq 6 \mathrm{~mL} / \mathrm{kg}, \%$ & $272(31.0)$ & $56(23.4)$ & $216(33.8)$ & 0.003 \\
\hline $\mathrm{V}_{\mathrm{T}}, \mathrm{PBW} \leq 8 \mathrm{~mL} / \mathrm{kg}, \%$ & $808(92.0)$ & $202(84.5)$ & $606(94.8)$ & $<0.001$ \\
\hline $\mathrm{V}_{\mathrm{T}}, \mathrm{PBW} \leq 10 \mathrm{~mL} / \mathrm{kg}, \%$ & 874 (99.5) & 238 (99.6) & $636(99.5)$ & 1.000 \\
\hline PEEP, $\mathrm{cmH}_{2} \mathrm{O}$ & $13.2[11.3,15.0]$ & $12.7[10.7,14.0]$ & $13.3[11.7,15.0]$ & 0.002 \\
\hline Peak pressure, $\mathrm{cmH}_{2} \mathrm{O}$ & $27.0[24.0,30.0]$ & $27.2[24.7,30.2]$ & $27.0[24.0,30.0]$ & 0.116 \\
\hline Driving pressure, $\mathrm{cmH}_{2} \mathrm{O}$ & $13.8[12.0,16.0]$ & $14.5[12.4,16.9]$ & $13.5[11.8,15.8]$ & $<0.001$ \\
\hline Mechanical power, J/min & $18.9[15.5,22.9]$ & $16.8[14.0,20.0]$ & $19.8[16.5,23.7]$ & $<0.001$ \\
\hline Compliance, $\mathrm{mL} / \mathrm{cmH}_{2} \mathrm{O}$ & $32.9[27.5,40.1]$ & $27.6[22.6,32.2]$ & $35.2[29.6,42.7]$ & $<0.001$ \\
\hline Respiratory rate, bpm & $22.0[20.0,24.2]$ & $22.0[20.0,25.0]$ & $22.0[20.0,24.0]$ & 0.257 \\
\hline $\mathrm{FiO}_{2}, \%$ & $0.5[0.4,0.6]$ & $0.5[0.4,0.6]$ & $0.5[0.4,0.6]$ & 0.505 \\
\hline $\mathrm{SpO}_{2}, \%$ & $95.0[93.6,96.4]$ & $95.0[93.5,96.2]$ & $95.0[93.7,96.5]$ & 0.588 \\
\hline $\mathrm{etCO}_{2}, \mathrm{mmHg}$ & $37.5[33.1,42.4]$ & $37.0[32.4,42.1]$ & $37.5[33.4,42.6]$ & 0.351 \\
\hline Heart rate, beats per min & $81.0[70.0,93.0]$ & $80.4[71.0,93.8]$ & $81.1[69.7,93.0]$ & 0.713 \\
\hline Mean arterial pressure, $\mathrm{mmHg}$ & $76.4[71.5,82.3]$ & $76.2[71.9,82.0]$ & $76.5[71.3,82.5]$ & 0.930 \\
\hline $\mathrm{pH}$ & $7.4[7.3,7.4]$ & $7.4[7.3,7.4]$ & $7.4[7.3,7.4]$ & 0.259 \\
\hline Lactate, mmol/L & $1.2[1.0,1.5]$ & $1.2[1.0,1.5]$ & $1.2[1.0,1.5]$ & 0.755 \\
\hline $\mathrm{PaO}_{2}$ & $80.0[72.9,90.7]$ & $79.8[72.2,91.1]$ & $80.1[73.0,89.9]$ & 0.823 \\
\hline $\mathrm{P} / \mathrm{F}$ ratio & $174.2[142.9,208.6]$ & $172.7[135.6,210.0]$ & $174.6[145.0,208.0]$ & 0.549 \\
\hline $\mathrm{PaCO}_{2}, \mathrm{mmHg}$ & $45.1[40.5,51.2]$ & $44.0[40.0,50.1]$ & $45.4[41.0,51.8]$ & 0.056 \\
\hline Prone positioning & $325(47.6)$ & $95(49.2)$ & $230(46.9)$ & 0.610 \\
\hline Duration of prone positioning & $15.0[11.0,22.0]$ & $16.0[11.0,23.0]$ & $14.0[11.0,20.0]$ & 0.129 \\
\hline Minute ventilation & $9.7[8.5,11.2]$ & $8.6[7.5,9.7]$ & $10.2[8.9,11.5]$ & $<0.001$ \\
\hline Ventilatory ratio & $1.7[1.4,2.0]$ & $1.7[1.4,2.1]$ & $1.7[1.4,2.0]$ & 0.030 \\
\hline Recruitment maneuver & $16(2.8)$ & $4(2.3)$ & $12(3.0)$ & 0.787 \\
\hline
\end{tabular}

Data are median (quartile 25\%-quartile 75\%) or no (\%). Percentages may not total 100 because of rounding.

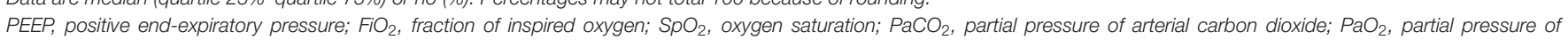
arterial oxygen.

"Of 934 patients who received controlled ventilation on at least one timepoint of data collection, 908 received controlled ventilation at day 1.

ventilation with a $\mathrm{V}_{\mathrm{T}, \mathrm{PBW}}$ above this upper threshold of what is generally accepted as safe. The use of a high $\mathrm{V}_{\mathrm{T}}$ is associated with a higher mortality and morbidity in ICU patients $(5,6,13-$ $15,19-21)$. An earlier analysis showed that a one SD increases in $\mathrm{V}_{\mathrm{T}}$, PBW meant an increase of $28 \%$ in 28 -day mortality (5). The finding that females received ventilation with a higher median $\mathrm{V}_{\mathrm{T}}$ than males in this cohort is in line with results from several investigations originating from before the COVID-19 pandemic $(13-16,44)$. It interesting to note that $\mathrm{V}_{\mathrm{T}}$, in both females and males, was lower than in those previous cohorts, suggesting a temporal trend toward the use of lower $\mathrm{V}_{\mathrm{T}}$ in critically ill patients (16). Despite the improved use of LTVV, however, differences between females and males persist.

Several reports on ventilated in patients with COVID-19 show a higher mortality in male patients $(5,22-30)$. This was also found in the current cohort. Interestingly, another study reported that the mortality of severely ill premenopausal but not post-menopausal female patients with COVID-19 are lower than age-matched male patients (31). The LUNG SAFE study, before COVID-19, did not find sex differences in mortality, but in that cohort, females had a shorter duration of invasive ventilation and a lower length of ICU stay (15). The reasons why male patients with COVID-19 have higher mortality remains uncertain. Biological factors, hormone factors such as estrogen, and factors related to the activity of X-linked genes have been suggested (31-34) and also sociocultural factors could play a role (34). It could also be interesting to look into the possible benefit of inhalation corticosteroids. In the current cohort, female patients had a significantly higher usage of inhalation corticosteroids as home medication. A total of 2 randomized clinical trials showed that using intravenous corticosteroids could reduce mortality $(35,36)$. These findings are confirmed in a recent meta-analysis (37). However, it is important to point out the difference between administration, i.e., intravenous vs. inhalation, and setting, i.e., during hospital admission vs. home medication. 


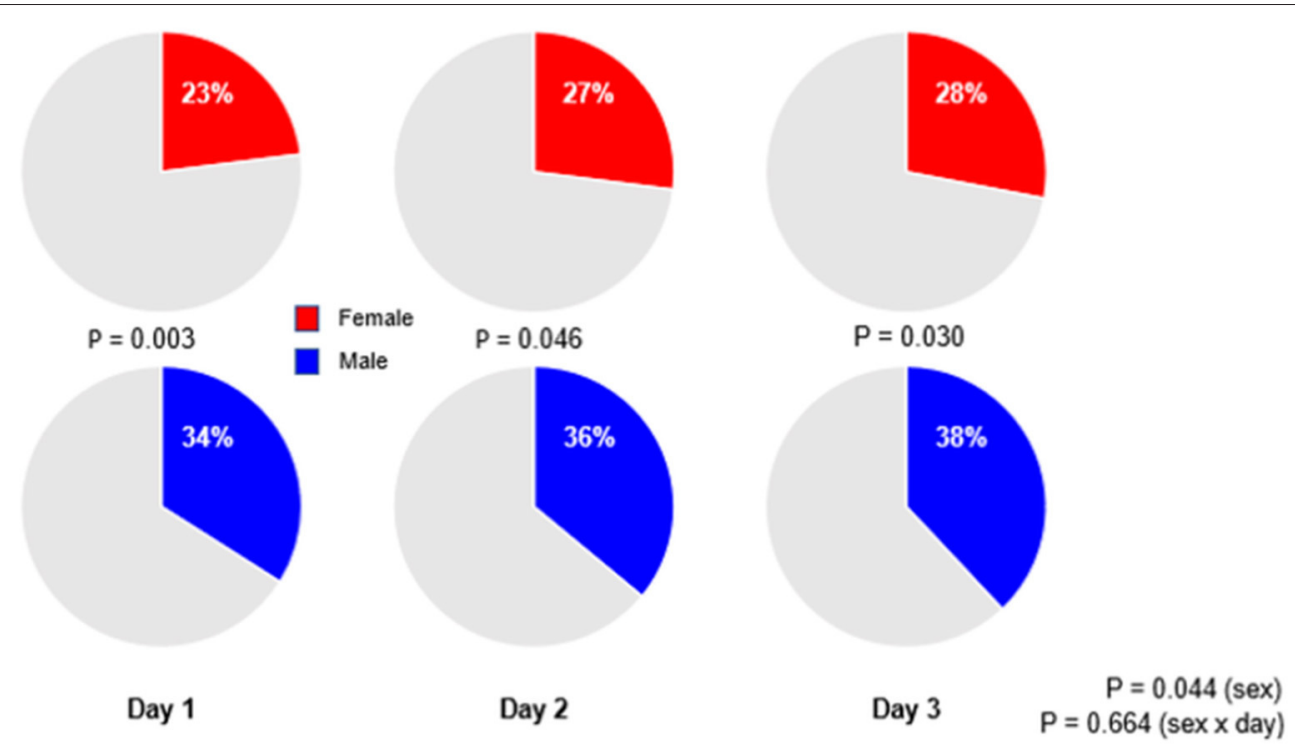

FIGURE 4 | Percentages of patients receiving low tidal volume ventilation. Significant $p$-value for the sex reflects the overall test for difference between sex over the days, while the $p$-value for the sex $\times$ year interaction evaluates if change over time differed by sex.

TABLE 4 | Mediation analysis.

\section{Adjusted absolute difference $(95 \% \mathrm{Cl})^{\mathrm{a}} \quad p$-value}

Univariable mediation model

Body height as mediator

Total effect of sex

Average causal

mediation effect of

body height

Average direct effect of

female sex

Body weight as mediator

Total effect of sex

Average causal

mediation effect of

body weight

Average direct effect of

female sex

Body height and weight as mediators*

Total effect of sex

Average causal

mediation effect of

body height

Average causal

mediation effect of

body weight

Average direct effect of

female sex

${ }^{a}$ All estimated were generated after 10,000 simulations.

${ }^{*} \mathrm{Cl}$ estimated from robust clustered standard errors.

The outcome advantage of female patients, however, should not withhold ICU doctors and nurses from using a correct $\mathrm{V}_{\mathrm{T}}$, seen the advantage of LTVV that has been found in pre-COVID-19 studies and in COVID-19 studies. In fact, this could increase the outcome differences between females and males.

Several studies in patients with non-COVID-19 have shown sex differences in important aspects of care in critically ill patients $(7,38-41)$. For instance-among patients with sepsis or shock, females are less likely to receive deep venous thrombosis prophylaxis or invasive ventilation, but are more likely to receive red blood cell transfusions (40). On the contrary, males receive "more intense" care, including placement of the central catheters for infusion of vasoactive medication (38) and invasive ventilation $(38,39)$. It is uncertain if similar differences, i.e., in non-ventilatory care, exist in patients with COVID-19 as well.

Of note, while $\mathrm{V}_{\mathrm{T}, \mathrm{PWB}}$ was higher in the female patients, $\mathrm{V}_{\mathrm{T}, \mathrm{ABW}}$ was higher in the male patients. It should be noticed, however, that the male patients had a significantly higher body mass index (BMI) compared with the females.

Next to the finding that female patients are ventilated with higher $\mathrm{V}_{\mathrm{T}, \mathrm{PBW}}$, it is seen that PEEP was lower and $\triangle \mathrm{P}$ was higher. These differences were rather small, and probably, therefore, less meaningful, and were only present at day 1 . There was a remarkable difference in median Crs between the sexes. This finding is in line with the results of the earlier studies in patients with ARDS before COVID-19 $(15,42)$. The difference in Crs might be explained by differences in height (42). Further research may reveal associations between other anthropometric factors and Crs.

The findings of the mediation analysis are in line with findings of the previous studies in patients in the ICU (16) and in the operating room (12). In contrary to previous findings, we see that differences are only partly explained by sex per se. The actual body weight mediated the sex inequality in the use of LTVV in a model as a single factor, but not in the model using also body height. 
Our findings point out the importance of using reliable methods to measure the height of the patients.

This analysis has some limitations; first, we only collected data during the first 4 calendar days of ventilation, and we cannot exclude the possibility that ventilation practices beyond these days remain different. Seen the observational nature of the study, we could not control for the unmeasured confounders. Also, the knowledge that ventilation data were being captured could have interfered with daily practice. The selection of ICUs was based on the personal contacts, which could have resulted in an overrepresentation of ICUs with more experience in lung-protective ventilation, including the use of LTVV, and the willingness to participate could have led to selection bias. Another limitation is that because this study was a national study, its worldwide generalizability is uncertain. Finally, the PRoVENT-COVID study did not collect the type of oxygen support before intubation. Early application of HFNC (high-flow nasal cannula) in the mild stage of ARDS may reduce mortality in the elderly patients with severe COVID-19 pneumonia (43). Further research should look into the influence of HFNC and should consider grouping the patients by age to see the impact of age on the use of LTVV in general and in female patients.

\section{CONCLUSION}

In this cohort of patients with ARDS related to COVID-19 who required invasive ventilation in the first wave of the national outbreak in the Netherlands, females received LTVV less often than males. Alike in the previous studies, in this cohort, the difference in the use of LTVV was driven by the anthropometric factors more than by sex per se. This information could be helpful in the proper titration of $\mathrm{V}_{\mathrm{T}}$ in critically ill patients with COVID-19 and beyond.

\section{DATA AVAILABILITY STATEMENT}

The raw data supporting the conclusions of this article will be made available by the authors, without undue reservation.

\section{AUTHOR CONTRIBUTIONS}

PS, MS, and FP were involved in the conceptualization, methodology, and worked with drafting of the manuscript.

\section{REFERENCES}

1. Wu C, Chen X, Cai Y, Xia J, Zhou X, Xu S, et al. Risk factors associated with acute respiratory distress syndrome and death in patients with coronavirus disease 2019 pneumonia in Wuhan, China. JAMA Intern Med. (2020) 180:934-43. doi: 10.1001/jamainternmed.2020.0994

2. Bennett S, Tafuro J, Mayer J, Darlington D, Wong CW, Muntean EA, et al. Clinical features and outcomes of adults with coronavirus disease 2019: a systematic review and pooled analysis of the literature. Int J Clin Pract. (2021) 75:e13725. doi: 10.1111/ijcp.13725

3. Brower RG, Matthay MA, Morris A, Schoenfeld D, Thompson BT, Wheeler A. Ventilation with lower tidal volumes as compared with traditional tidal
Acquisition, analysis, or interpretation of data was done by all the authors. Critical revision of the manuscript for important intellectual content by all the other authors. Statistical analysis was done by PS and AN. Administrative, technical, or material support was done by MS. MS, FP, and AN supervised the work.

\section{FUNDING}

This work was supported by Amsterdam University Medical Centers, Location Academic Medical Center, Amsterdam, the Netherlands.

\section{THE PROVENT-COVID COLLABORATIVE GROUP}

Investigators (in alphabetic order) J. P. van Akkeren; A. G. Algera; C. K. Algoe; R. B. van Amstel; O. L. Baur; P. van de Berg; D. C. J. J. Bergmans; D. I. van den Bersselaar; F. A. Bertens; A. J. G. H. Bindels; M. M. de Boer; S. den Boer; L. S. Boers; M. Bogerd; L. D. J. Bos; M. Botta; J. S. Breel; H. de Bruin; S. de Bruin; C. L. Bruna; L. A. Buiteman-Kruizinga; O. Cremer; R. M. Determann; W. Dieperink; D. A. Dongelmans; H. S. Franke; M. S. Galek Aldridge; M. J. de Graaff; L. A. Hagens; J. J. Haringman; N. F. L. Heijnen; S. Hiel; S. T. van der Heide; P. L. J. van der Heiden; L. L. Hoeijmakers; L. Hol; M. W. Hollmann; M. E. Hoogendoorn; J. Horn; R. van der Horst; E. L. K. Ie; D. Ivanov; N. P. Juffermans; E. Kho; E. S. de Klerk; A. W. M. Koopman; M. Koopmans; S. Kucukcelebi; M. A. Kuiper; D. W. de Lange; D. M. van Meenen; Ignacio Martin-Loeches, Guido Mazzinari; N. van Mourik; S. G. Nijbroek; M. Onrust; E. A. N. Oostdijk; F. Paulus; C. J. Pennartz; J. Pillay; L. Pisani; I. M. Purmer; T. C. D. Rettig; J. P Roozeman; M. T. U. Schuijt; M. J. Schultz; A. Serpa Neto; M. E. Sleeswijk; M. R. Smit; P. E. Spronk; W. Stilma; A. C. Strang; A. M. Tsonas; P. R Tuinman; C. M. A. Valk; F. L. Veen; A. P. J. Vlaar; L. I. Veldhuis; P. van Velzen; W. H. van der Ven; P. van Vliet; P. van der Voort; H. H. van der Wier; L. van Welie; H. J. F. T. Wesselink; B. van Wijk; T. Winters; W. Y. Wong; and A. R. H. van Zanten.

\section{SUPPLEMENTARY MATERIAL}

The Supplementary Material for this article can be found online at: https://www.frontiersin.org/articles/10.3389/fmed. 2021.780005/full\#supplementary-material volumes for acute lung injury and the acute respiratory distress syndrome. $N$ Engl J Med. (2000) 342:1301-8. doi: 10.1056/nejm200005043421801

4. Griffiths MJD, Mcauley DF, Perkins GD, Barrett N, Blackwood B, Boyle A, et al. Guidelines on the management of acute respiratory distress syndrome. BMJ Open Respir Res. (2019) 6:e000420. doi: 10.1136/bmjresp-2019-000420

5. Botta M, Tsonas AM, Pillay J, Boers LS, Algera AG, Bos LDJ, et al. Ventilation management and clinical outcomes in invasively ventilated patients with COVID-19 (PRoVENT-COVID): a national, multicentre, observational cohort study. Lancet Respir Med. (2020) 9:139-48. doi: 10.1016/s2213-2600(20)30459-8

6. Ferreira JC, Ho Y-L, Besen BAMP, Malbouisson LMS, Taniguchi LU, Mendes PV, et al. Protective ventilation and outcomes of critically ill 
patients with COVID-19: a cohort study. Ann Intensive Care. (2021) 11:92. doi: 10.1186/s13613-021-00882-w

7. Fernandez-Bustamante A, Wood CL, Tran ZV, Moine P. Intraoperative ventilation: incidence and risk factors for receiving large tidal volumes during general anesthesia. BMC Anesthesiol. (2011) 11:22. doi: 10.1186/1471-2253-11-22

8. Karalapillai D, Weinberg L, Galtieri J, Glassford N, Eastwood G, Darvall $\mathrm{J}$, et al. Current ventilation practice during general anaesthesia: a prospective audit in Melbourne, Australia. BMC Anesthesiol. (2014) 14:85. doi: 10.1186/1471-2253-14-85

9. Bender SP, Paganelli WC, Gerety LP, Tharp WG, Shanks AM, Housey M, et al. Intraoperative lung-protective ventilation trends and practice patterns: a report from the multicenter perioperative outcomes group. Anesth Analg. (2015) 121:1231-9. doi: 10.1213/ane.0000000000000940

10. Wanderer JP, Ehrenfeld JM, Epstein RH, Kor DJ, Bartz RR, FernandezBustamante A, et al. Temporal trends and current practice patterns for intraoperative ventilation at U.S. academic medical centers: a retrospective study. BMC Anesthesiol. (2015) 15:40. doi: 10.1186/s12871-015-0010-3

11. Kowa CY, Jin Z, Longbottom R, Cullinger B, Walker P. Risk factors for excessive tidal volumes delivered during intraoperative mechanical ventilation, a retrospective study. Int J Physiol Pathophysiol Pharmacol. (2020) 12:51-7.

12. Nijbroek SG, Hol L, Swart P, Hemmes SNT, Serpa Neto A, Binnekade JM, et al. Sex difference and intra-operative tidal volume: insights from the LAS VEGAS study. Eur J Anaesthesiol. (2021) 38:103441. doi: 10.1097/eja.0000000000001476

13. Gajic O, Dara SI, Mendez JL, Adesanya AO, Festic E, Caples SM, et al. Ventilator-associated lung injury in patients without acute lung injury at the onset of mechanical ventilation. Crit Care Med. (2004) 32:181724. doi: 10.1097/01.ccm.0000133019.52531.30

14. Lellouche F, Dionne S, Simard S, Bussieres J, Dagenais F. High tidal volumes in mechanically ventilated patients increase organ dysfunction after cardiac surgery. Anesthesiology. (2012) 116:1072-82. doi: 10.1097/ALN.0b013e3182522df5

15. McNicholas BA, Madotto F, Pham T, Rezoagli E, Masterson CH, Horie S, et al. Demographics, management and outcome of females and males with acute respiratory distress syndrome in the LUNG SAFE prospective cohort study. Eur Respir J. (2019) 54:1900609. doi: 10.1183/13993003.00609-2019

16. Swart P, Deliberato RO, Johnson AEW, Pollard TJ, Bulgarelli L, Pelosi P, et al. Impact of sex on use of low tidal volume ventilation in invasively ventilated ICU patients-a mediation analysis using two observational cohorts. PLoS ONE. (2021) 16:e0253933. doi: 10.1371/journal.pone.0253933

17. Ranieri VM, Rubenfeld GD, Thompson BT, Ferguson ND, Caldwell E, Fan E, et al. Acute respiratory distress syndrome: the Berlin definition. JAMA. (2012) 307:2526-33. doi: 10.1001/jama.2012.5669

18. Angus DC, Derde L, Al-Beidh F, Annane D, Arabi Y, Beane A, et al. Effect of hydrocortisone on mortality and organ support in patients with severe COVID-19: the REMAP-CAP COVID-19 corticosteroid domain randomized clinical trial. JAMA. (2020) 324:1317-29. doi: 10.1001/jama.2020.17022

19. Serpa Neto A, Hemmes SN, Barbas CS, Beiderlinden M, Biehl M, Binnekade JM, et al. Protective versus conventional ventilation for surgery: a systematic review and individual patient data meta-analysis. Anesthesiology. (2015) 123:66-78. doi: 10.1097/aln.0000000000000706

20. Madotto F, Pham T, Bellani G, Bos LD, Simonis FD, Fan E, et al. Resolved versus confirmed ARDS after 24 h: insights from the LUNG SAFE study. Intensive Care Med. (2018) 44:564-77. doi: 10.1007/s00134-018-5152-6

21. Lanspa MJ, Peltan ID, Jacobs JR, Sorensen JS, Carpenter L, Ferraro JP, et al. Driving pressure is not associated with mortality in mechanically ventilated patients without ARDS. Crit Care. (2019) 23:424. doi: 10.1186/s13054-019-2698-9

22. Azzolina D, Magnani C, Gallo E, Ferrante D, Gregori D. [Gender and age factors affecting the mortality during the COVID-19 epidemic in Italy]. Epidemiol Prev. (2020) 44:252-9. doi: 10.19191/ep20.5-6.S2.125

23. Chen J, Bai H, Liu J, Chen G, Liao Q, Yang J, et al. Distinct clinical characteristics and risk factors for mortality in female inpatients with coronavirus disease 2019 (COVID-19): a sex-stratified, largescale cohort study in Wuhan, China. Clin Infect Dis. (2020) 71:3188-95. doi: 10.1093/cid/ciaa920
24. Jin JM, Bai P, He W, Wu F, Liu XF, Han DM, et al. Gender differences in patients with COVID-19: focus on severity and mortality. Front Public Health. (2020) 8:152. doi: 10.3389/fpubh.2020.00152

25. Kragholm K, Andersen MP, Gerds TA, Butt JH, Østergaard L, Polcwiartek C, et al. Association between male sex and outcomes of coronavirus disease 2019 (Covid-19) - a Danish nationwide, register-based study. Clin Infect Dis. (2020) 73:e4025-30. doi: 10.1093/cid/ciaa924

26. Nasiri MJ, Haddadi S, Tahvildari A, Farsi Y, Arbabi M, Hasanzadeh $\mathrm{S}$, et al. COVID-19 clinical characteristics, and sex-specific risk of mortality: systematic review and meta-analysis. Front Med. (2020) 7:459. doi: 10.3389/fmed.2020.00459

27. Takahashi T, Ellingson MK, Wong P, Israelow B, Lucas C, Klein J, et al. Sex differences in immune responses that underlie COVID-19 disease outcomes. Nature. (2020) 588:315-20. doi: 10.1038/s41586-020-2700-3

28. Pijls BG, Jolani S, Atherley A, Derckx RT, Dijkstra JIR, Franssen GHL, et al. Demographic risk factors for COVID-19 infection, severity, ICU admission and death: a meta-analysis of 59 studies. BMJ Open. (2021) 11:e044640. doi: 10.1136/bmjopen-2020-044640

29. Tejpal A, Gianos E, Cerise J, Hirsch JS, Rosen S, Kohn N, et al. Sexbased differences in COVID-19 outcomes. J Womens Health. (2021) 30:492501. doi: 10.1089/jwh.2020.8974

30. Vahidy FS, Pan AP, Ahnstedt H, Munshi Y, Choi HA, Tiruneh Y, et al. Sex differences in susceptibility, severity, and outcomes of coronavirus disease 2019: cross-sectional analysis from a diverse US metropolitan area. PLoS ONE. (2021) 16:e0245556. doi: 10.1371/journal.pone.0245556

31. Liu D, Ding HL, Chen Y, Chen DH, Yang C, Yang LM, et al. Comparison of the clinical characteristics and mortalities of severe COVID-19 patients between pre- and post-menopause women and age-matched men. Aging. (2021) 13:21903-13. doi: 10.18632/aging.203532

32. Ambrosino I, Barbagelata E, Corbi G, Ciarambino T, Politi C, Moretti AM. Gender differences in treatment of coronavirus disease-2019. Monaldi Arch Chest Dis. (2020) 90:646-56. doi: 10.4081/monaldi.2020.1508

33. Van Zeggeren IE, Boelen A, Van De Beek D, Heijboer AC, Vlaar APJ, Brouwer MC. Sex steroid hormones are associated with mortality in COVID19 patients: level of sex hormones in severe COVID-19. Medicine. (2021) 100:e27072. doi: 10.1097/md.0000000000027072

34. Viveiros A, Rasmuson J, Vu J, Mulvagh SL, Yip CYY, Norris CM, et al. Sex differences in COVID-19: candidate pathways, genetics of ACE2, and sex hormones. Am J Physiol Heart Circ Physiol. (2021) 320:H296304. doi: 10.1152/ajpheart.00755.2020

35. Edalatifard M, Akhtari M, Salehi M, Naderi Z, Jamshidi A, Mostafaei S, et al. Intravenous methylprednisolone pulse as a treatment for hospitalised severe COVID-19 patients: results from a randomised controlled clinical trial. Eur Respir J. (2020) 56:2002808. doi: 10.1183/13993003.02808-2020

36. Horby P, Lim WS, Emberson JR, Mafham M, Bell JL, Linsell L, et al. Dexamethasone in hospitalized patients with covid-19. N Engl J Med. (2021) 384:693-704. doi: 10.1056/NEJMoa2021436

37. Yu GQ, Jiang ZH, Yang ZB, Jiang SQ, Quan XQ. The effect of glucocorticoids on mortality in severe COVID-19 patients: evidence from 13 studies involving 6612 cases. Medicine. (2021) 100:e27373. doi: 10.1097/md.0000000000 027373

38. Valentin A, Jordan B, Lang T, Hiesmayr M, Metnitz PG. Gender-related differences in intensive care: a multiple-center cohort study of therapeutic interventions and outcome in critically ill patients. Crit Care Med. (2003) 31:1901-7. doi: 10.1097/01.Ccm.0000069347.78151.50

39. Fowler RA, Sabur N, Li P, Juurlink DN, Pinto R, Hladunewich MA, et al. Sexand age-based differences in the delivery and outcomes of critical care. CMAJ. (2007) 177:1513-9. doi: 10.1503/cmaj.071112

40. Pietropaoli AP, Glance LG, Oakes D, Fisher SG. Gender differences in mortality in patients with severe sepsis or septic shock. Gend Med. (2010) 7:422-37. doi: 10.1016/j.genm.2010.09.005

41. Chapa J, Nonas S. Differences in lung protective ventilation use in female vs male organ donors. Chest. (2018) 154:1101A. doi: 10.1016/j.chest.2018.08.1001

42. Vandenbunder B, Ehrmann S, Piagnerelli M, Sauneuf B, Serck N, Soumagne $\mathrm{T}$, et al. Static compliance of the respiratory system in COVID-19 related ARDS: an international multicenter study. Crit Care. (2021) 25:52. doi: $10.1186 /$ s13054-020-03433-0 
43. Deng L, Lei S, Wang X, Jiang F, Lubarsky DA, Zhang L, et al. Course of illness and outcomes in older COVID-19 patients treated with HFNC: a retrospective analysis. Aging. (2021) 13:15801-14. doi: 10.18632/aging. 203224

44. (2018). ESICM LIVES 2018: Paris, France. 20-24 October 2018. Intensive Care Med Exp 6:40. doi: 10.1186/s40635-018-0201-6

Conflict of Interest: AN reports personal fees from Dräger, outside of the submitted work. MS reports personal fees from the Hamilton Medical, outside of the submitted work.

The remaining authors declare that the research was conducted in the absence of any commercial or financial relationships that could be construed as a potential conflict of interest.
Publisher's Note: All claims expressed in this article are solely those of the authors and do not necessarily represent those of their affiliated organizations, or those of the publisher, the editors and the reviewers. Any product that may be evaluated in this article, or claim that may be made by its manufacturer, is not guaranteed or endorsed by the publisher.

Copyright (C) 2022 Swart, Nijbroek, Paulus, Neto and Schultz. This is an open-access article distributed under the terms of the Creative Commons Attribution License (CC $B Y)$. The use, distribution or reproduction in other forums is permitted, provided the original author(s) and the copyright owner(s) are credited and that the original publication in this journal is cited, in accordance with accepted academic practice. No use, distribution or reproduction is permitted which does not comply with these terms. 